\title{
Estimating Accelerated Life Test Using Constant Stress for Inverse Gaussian Distribution under Type-II Censoring
}

\section{By}

\section{Reda Mohamed Hasan}

Department of Statistics, Faculty of Commerce, AL-Azhar University, Girls' Branch, Cairo, Egypt, Mail:eslam_dfg2002@yahoo.com. 


\title{
Estimating Accelerated Life Test Using Constant Stress for Inverse Gaussian Distribution under Type-II Gensoring
}

\author{
S. A-EL. Shaban ${ }^{1}$, F. A. khalil ${ }^{2}$ H. M. Aly ${ }^{3}$ and R. M. Hasan ${ }^{4}$
}

\section{Ahstract}

In this paper, the statistical inference of accelerated life tests under Type-II censoring is studied for constant stress accelerated life tests. It is assumed that the lifetime at design stress has inverse Gaussian distribution. The scale parameter of the lifetime distribution at constant stress levels is assumed to be an inverse power law function of the stress level. The model parameters and the reliability function are estimated using the maximum likelihood method. Asymptotic Fisher information matrix, the asymptotic variance-covariance matrix and the confidence intervals are founded. The predictive value of the scale parameter and the reliability function under the usual conditions are obtained under Type-II censoring. Finally, some numerical illustrations by using Monte Carlo simulations are introduced to illustrate the proposed procedures.

Keywords and Phrases: Accelerated life test; Constant stress; Type-II censoring; Maximum likelihood estimation; Fisher information matrix; Inverse Gaussian distribution.

\section{Introduction}

Today's increasing market competition and higher customer expectations are driving manufacturers to design and produce highly

\footnotetext{
${ }^{1}$ Professor of Statistics, Department of Mathematical Statistics, Institute of Statistical Studies and Research, Cairo University, Cairo, Egypt.

${ }^{2}$ Associate Professor of Statistics, Department of Statistics, Faculty of Commerce, AL-Azhar University, Girls' Branch, Cairo, Egypt. Mail: dr_fkhalil@yahoo.com.

${ }^{3}$ Associate Professor of Statistics, Department of Statistics, Faculty of Economics \& Political Science, Cairo University, Cairo, Egypt, Mail: han_m_hasan@yahoo.com.

${ }^{4}$ Ph.D. Student, Department of Statistics, Faculty of Commerce, AL-Azhar University, Girls' Branch, Cairo, Egypt, Mail:eslam_dfg2002@yahoo.com.
} 
reliable products. It is important to assess and predict the reliability of a product during the design and development stage because the time-tomarket is getting shorter and shorter. Reliability assessment usually depends on experimental life tests to obtain failure data for lifetime analysis. Because life tests are expensive and the decision made based on the life tests affects the total life-cycle cost, they need to be carefully planned and analyzed. For this reason, Accelerated Life Tests (ALT) are preferred to be used in manufacturing industries to obtain enough failure data, in a short period of time, necessary to make inference regarding its relationship with external stress variables. Accelerated testing allows the experimenter to increase these stress levels to obtain information on the parameters of the life distributions more quickly than would be possible under normal operating conditions. This process requires a model relating the level of stress and the failure time distributions. Several models are available in literature like the inverse power law model, the Arrhenius model and the Log-linear model, for more details, see Nelson (1990).

The obtained data may be incomplete or it may include uncertainty about the failure time. There are three types of possible censoring schemes, right censoring, left censoring, and interval censoring. The most common schemes are time censoring, and failure-censoring. Time censored data is also known as Type-I censored. It occurs when the life test is terminated at a specified time, before all units have failed. Data are failure censored or Type-II censored if the test is terminated after a specified number of failures.

In real life, different types of stress loading may be considered when performing an accelerated test. The common types are constant stress, step stress, and progressive stress. The most common stress loading is constant stress.

In Constant Stress Accelerated Life Test (CSALT), the stress is kept at a constant level of stress throughout the life of the test, i.e., each unit is run at a constant high stress level until the occurrence of failure or the observation is censored. Practically, most devices such as lamps, semiconductors and microelectronics are run at a constant stress. Many authors have studied statistical inference of CSALT, for example, Lawless (1976), McCool (1980), Bai and Chung (1989), Bugaighis (1990), Watkins 
(1991), Abdel Ghaly et al. (1998), El-Dessouky (2001),Kim and Bai (2002), AL-Hussaini and Abdel-Hamid $(2004,2006)$ and Watkins and John (2008) and Attia et al. (2011).

The Inverse Gaussian (IG) distribution is a natural alternative candidate to the normal distribution for modeling non-negative data with positive skewness. Tweedie (1957) proposed the name IG distribution since he found an inverse relationship between the cumulant generating functions of this distribution and those of Gaussian distributions. For more details about the IG distribution, see Chhikara and Folks (1989), Seshadri (1993) and Johnson et al. (1995).

The most used form of the Generalized Inverse Gaussian (GIG) distribution is the IG also called the Wald distribution. The IG distribution belongs to a two parameter family of distributions. The interest for this distribution is a result of its attractive statistical and probabilistic properties. For example, the IG distribution belongs to the exponential family the IG distribution family, it has the reproductive property and it possesses similar inferential properties to that of the normal model, for more details see Mudholkar and Natarajan (2002).

The Probability Density Function (pdf) of the IG distribution can be represented in several different forms each of which would be convenient for some purpose in the area of reliability engineering. This distribution was long known in the literature of stochastic process and its potential in statistical applications is increasingly recognized in recent years. The IG distribution is also used in the area of natural and social sciences, i.e., tracer dilution curves by Wise (1966), lengths of strikes by Lancaster (1972), noise intensity by Marcus (1975) and hospital stays by Eaton and Whitmore (1977). Also, Bannerjee and Bhattacharyya (1976) applied this distribution in marketing research and Chhikara and Folks (1976) consider applications of the IG distribution in life testing.

This paper is organized as follows: in Section 2, the underlying distribution and the test method are described. In Section 3, the Maximum Likelihood (ML) estimators of the model parameters with their properties and the confidence limits under Type-II censoring are obtained. Finally, the simulation studies needed for illustrating the theoretical results are presented in Section 4. 


\section{The Model}

\subsection{The Inverse Gaussian Distribution}

The inverse Gaussian distribution with 2-parameter $\mu$, and $\lambda$, which is denoted by $\mathrm{IG}(\mu, \lambda)$, its pdf is given by

$$
f(t ; \mu ; \lambda)=\left(\frac{\lambda}{2 \pi}\right)^{\frac{1}{2}} t^{\frac{-3}{2}} \exp \left(\frac{-\lambda(t-\mu)^{2}}{2 \mu^{2} t}\right) \quad t>0, \mu, \lambda>0 .
$$

The mean and the variance of this distribution are $\mu$ and $\frac{\mu^{3}}{\lambda}$, respectively.

The reliability function takes the form

$$
R(t)=1-\left\{\Phi\left[\left(\frac{\lambda}{t}\right)^{\frac{1}{2}}\left(\frac{t}{\mu}-1\right)\right]+\exp \left(\frac{2 \lambda}{\mu}\right) \Phi\left[-\left(\frac{\lambda}{t}\right)^{\frac{1}{2}}\left(\frac{t}{\mu}+1\right)\right]\right\},
$$

Where $\Phi(a)$ is the cdf of standard normal distribution about a.

And the corresponding failure rate is given by

$$
h(t)=\frac{\left(\frac{\lambda}{2 \pi}\right)^{\frac{1}{2}}(t)^{\frac{-3}{2}} \exp \left(\frac{-\lambda(t-\mu)^{2}}{2 \mu^{2} t}\right)}{1-\Phi\left[\left(\frac{\lambda}{t}\right)^{\frac{1}{2}}\left(\frac{t}{\mu}-1\right)\right]-\exp \left(\frac{2 \lambda}{\mu}\right) \Phi\left[-\left(\frac{\lambda}{t}\right)^{\frac{1}{2}}\left(\frac{t}{\mu}+1\right)\right]} \quad t>0, \mu, \lambda>0
$$

\subsection{Assumptions}

The following assumptions can be assumed for the CSALT procedure

- There are k levels of high stress $V_{j}, j=1,2, \ldots, k$ in the experiment, and $V_{u}$ is the stress under usual conditions, where $V_{u}<V_{1}<V_{2}<\ldots<V_{K}$.

- A total of $\mathrm{n}$ units are divided into $n_{1}, n_{2}, n_{3}, \ldots, n_{K}$ units where $\sum_{j=1}^{K} n_{j}=n$.

- Each $_{n_{j}}, j=1,2, \ldots, k$ units in the experiment are run at a pre-specified constant stress

$V_{j}, j=1,2, \ldots, k$. 
- It is assumed that the stress affects only on the scale parameter of the underlying distribution.

- The failure times $t_{i j}, i=1,2, \ldots, r_{j}$, and $j=1,2, \ldots, k$ at stress levels $V_{j}, j=1,2, \ldots, k$ are the 2-parameter IG distribution with pdf

$$
f\left(t_{i j} ; \mu_{j}, \lambda\right)=\left(\frac{\lambda}{2 \pi}\right)^{\frac{1}{2}}\left(t_{i j}\right)^{-\frac{3}{2}} \exp \left(\frac{-\lambda\left(t_{i j}-\mu_{j}\right)^{2}}{2 \mu_{j}{ }_{j} t_{i j}}\right), \quad t_{i j}>0, \mu_{j}>0, \lambda>0 .
$$

The scale parameter $\mu_{j}, j=1,2, \ldots, k$ of the underlying lifetime distribution (2.4) is assumed to have an inverse power law function on stress levels, i.e,

$$
\mu_{j}=C S_{j}^{-p}, c>0, P>0 \quad \text { and } \quad S_{j}=\frac{V^{*}}{V_{j}} j=1,2, \ldots, k,
$$

where

$$
V^{*}=\prod_{j=1}^{K} V_{j}^{b_{j}}, b_{j}=\frac{r_{j}}{\sum_{j=1}^{K} r_{j}},
$$

where $\mathrm{C}$ is the constant of proportionality and $P$ is the power of the applied stress.

\section{Point and Interval Estimation Using Maximum Likelihood Method}

An additional to the common assumptions in Section (2.2), we assume the experiment is terminated at a pre-specified censoring number of failures $r_{j}$. Thus, the corresponding likelihood function will be as the following form

$\mathrm{L}(\mathrm{C}, \mathrm{P}, \lambda ; \underline{\mathrm{t}})=\prod_{j=1}^{K} a_{j} \prod_{i=1}^{r_{j}}\left(\left(\frac{\lambda}{2 \pi}\right)^{\frac{1}{2}} t_{i j}^{\frac{-3}{2}} \exp \left(\frac{-\lambda\left(t_{i j}-c s_{j}^{-p}\right)^{2} s_{j}^{2 p}}{2 c^{2} t_{i j}}\right)\right)\left[1-W_{j}\right]^{n_{j}-r_{j}}, C, p, \mu, \lambda>0$,

Where $a_{j}=\frac{n_{j} !}{\left(n_{j}-r_{j}\right) !}$, 
and $W_{j}=\Phi\left[\left(\frac{\lambda}{t_{r_{j} j}}\right)^{\frac{1}{2}}\left(\frac{t_{r_{j}} s_{j}^{p}}{c}-1\right)\right]+\exp \left(\frac{\lambda s_{j}^{p}}{c}\right) \Phi\left[-\left(\frac{\lambda}{t_{r_{j} j}}\right)^{\frac{1}{2}}\left(\frac{t_{r_{j}} s_{j}^{p}}{c}+1\right)\right]$, then

the log-likelihood function has the following form $\operatorname{lnL}(\mathrm{C}, \mathrm{P}, \lambda ; \underline{\mathrm{t}}) \propto \frac{1}{2} \ln \lambda \sum_{j=1}^{K} r_{j}-\frac{3}{2} \sum_{j=1}^{K} \sum_{i=1}^{r_{j}} \ln t_{i j}-\frac{\lambda}{2 c^{2}} \sum_{j=1}^{K} \sum_{i=1}^{r_{j}} \frac{\left(t_{i j}-c s_{j}^{-p}\right)^{2} s_{j}^{2 p}}{t_{i j}}+\sum_{j=1}^{K}\left(n_{j}-r_{j}\right) \ln \left(1-W_{j}\right)$.

\subsection{The Maximum Likelihood Estimators of the Parameters}

The first derivatives of the log-likelihood function (3.2) with respect to the unknown Parameters $C, P$ and $\lambda$ are given by:

$$
\begin{aligned}
& \frac{\partial \ln L}{\partial c}=\frac{\lambda}{c^{3}} \sum_{j=1}^{K} \sum_{i=1}^{r_{j}} s_{j}^{2 p} B_{i j}-\sum_{j=1}^{K} \frac{\left(n_{j}-r_{j}\right)}{\left(1-W_{j}\right)}\left\{D_{j}\left(\exp \left(G_{j}\right) \varphi\left(H_{j}\right)-\varphi\left(A_{j}\right)\right)-\frac{G_{j}}{c} \exp \left(G_{j}\right) \Phi\left(H_{j}\right)\right\}, \\
& \frac{\partial \ln L}{\partial p}=\frac{-2 \lambda}{c^{2}} \sum_{j=1 i=1}^{K} \sum_{i j}^{r_{j}} B_{j} s_{j}^{2 p} \ln \left(s_{j}\right)-\sum_{j=1}^{K} \frac{\left(n_{j}-r_{j}\right)}{\left(1-W_{j}\right)}\left\{\begin{array}{l}
\left.c D_{j} \ln s_{j}\left(\varphi\left(A_{j}\right)-\exp \left(G_{j}\right) \varphi\left(H_{j}\right)\right)\right\}, \\
+G_{j} \ln s_{j} \exp \left(G_{j}\right) \Phi\left(H_{j}\right)
\end{array}\right\} \\
& \frac{\partial \ln L}{\partial \lambda}=\frac{\sum_{j=1}^{K} r_{j}}{2 \lambda}-\frac{1}{2 c^{2}} \sum_{j=1 i=1}^{K} \sum_{j}^{r_{j}} \frac{B_{i j}^{2} s_{j}^{2 p}}{t_{i j}}-\sum_{j=1}^{K} \frac{\left(n_{j}-r_{j}\right)}{\left(1-W_{j}\right)}\left\{\begin{array}{l}
\frac{1}{2 \lambda}\left(A_{j} \varphi\left(A_{j}\right)-H_{j} \exp \left(G_{j}\right) \varphi\left(H_{j}\right)\right) \\
+\frac{G_{j}}{\lambda} \exp \left(G_{j}\right) \Phi\left(H_{j}\right)
\end{array}\right\},
\end{aligned}
$$

Where $\varphi$ is the pdf of standard normal distribution.

$$
\begin{aligned}
& B_{i j}=t_{i j}-c s_{j}^{-p}, D_{j}=\frac{\left(\lambda t_{r_{j} j}\right)^{\frac{1}{2}} s_{j}^{p}}{c^{2}}, A_{j}=\left(\frac{\lambda}{t_{r_{j} j}}\right)^{\frac{1}{2}}\left(\frac{t_{r_{j} j} s_{j}^{p}}{c}-1\right), G_{j}=\left(\frac{2 \lambda s_{j}^{p}}{c}\right), \\
& \text { and } H_{j}=-\left(\frac{\lambda}{t_{r_{j} j}}\right)^{\frac{1}{2}}\left(\frac{t_{r_{j} j} s_{j}^{p}}{c}+1\right) .
\end{aligned}
$$

Since the first derivatives (3.3) to (3.5) are non-linear equations, their solutions will be obtained numerically by using the MathCade program as will be seen in Section (5.1). 


\subsection{Interval Estimation}

The observed Fisher information matrix, as well as the asymptotic variance-covariance matrix of the MLEs is derived. Approximate Confidence Intervals (CI) for the parameters based on normal approximation to the asymptotic distribution of MLEs are derived. As indicated by Vander Wiel and Meeker (1990), the most common method to set confidence bounds for the parameters is to use the large-sample (asymptotic) normal distribution of the ML estimators.

In relation to the asymptotic variance-covariance matrix of the MLE of the parameters, it can be approximated by numerically inverting the observed Fisher-information matrix. The observed Fisher-information matrix is composed of the negative second derivatives of the natural logarithm of the likelihood function evaluated at the MLEs. It can be given by the following matrix:

$$
I=-\left[\begin{array}{ccc}
\frac{\partial^{2} \ln L}{\partial c^{2}} & \frac{\partial^{2} \ln L}{\partial p \partial c} & \frac{\partial^{2} \ln L}{\partial c \partial \lambda} \\
\frac{\partial^{2} \ln L}{\partial p \partial c} & \frac{\partial^{2} \ln L}{\partial p^{2}} & \frac{\partial^{2} \ln L}{\partial p \partial \lambda} \\
\frac{\partial^{2} \ln L}{\partial c \partial \lambda} & \frac{\partial^{2} \ln L}{\partial p \partial \lambda} & \frac{\partial^{2} \ln L}{\partial \lambda^{2}}
\end{array}\right] .
$$

The elements of the matrix I in (3.6) can be expressed by the following equations Follows:

$$
\begin{aligned}
& \frac{\partial^{2} \ln L}{\partial p^{2}}=\frac{-4 \lambda}{c^{2}} \sum_{j=1 i=1}^{K} \sum_{j}^{r_{j}} \mathrm{~s}_{j}^{2 p} \mathrm{~B}_{i j}\left(\ln \left(\mathrm{s}_{\mathrm{j}}\right)\right)^{2}-\sum_{j=1}^{K} \frac{\left(n_{j}-r_{j}\right)}{\left(1-W_{j}\right)^{2}}\left[\left(1-W_{j}\right)\left\{\eta_{j}+c D_{j} \ln s_{j}^{2}\left(\omega_{j}\right)\right\}+\zeta_{j}^{2}\right] \\
& \frac{\partial^{2} \ln L}{\partial c^{2}}=-\lambda \sum_{j=i=1}^{K} \sum_{i=1}^{r_{j} S_{j}^{2 p}} \frac{\left(c s_{j}^{p}+B_{i j}\right)}{t_{i j}}\left[\frac{\left(c \bar{s}_{j}^{p}+3 B_{i j}\right)}{c^{4}}\right]-\sum_{j=\left(1-W_{j}\right)^{2}}^{K}\left(\eta_{j}\right), \\
& \frac{\partial^{2} \operatorname{lnL}}{\partial \lambda^{2}}=\frac{-\sum_{\mathrm{j}=1}^{\mathrm{K}} \mathrm{r}_{\mathrm{j}}}{2 \lambda^{2}}-\sum_{\mathrm{j}=1}^{\mathrm{K}} \frac{\left(\mathrm{n}_{\mathrm{j}}-\mathrm{r}_{\mathrm{j}}\right)}{\left(1-\mathrm{W}_{\mathrm{j}}\right)^{2}}\left[\left(1-\mathrm{W}_{\mathrm{j}}\right)\left\{\frac{A_{j}}{4 \lambda^{2}} \alpha_{\mathrm{j}}+\sigma_{j}+\frac{\exp \left(G_{j}\right)}{\lambda} \kappa_{j}\right\}+\Omega_{j}^{2}\right] \text {, } \\
& \frac{\partial^{2} \ln L}{\partial p \partial c}=\frac{2 \lambda}{c^{3}} \sum_{j=1 i=1}^{K} \sum_{j}^{r_{j}} s_{j}^{p} \ln \left(s_{j}\right)\left(2 s_{j}^{p} t_{i j}-c\right)-\sum_{j=1}^{K} \frac{\left(n_{j}-r_{j}\right)}{\left(1-W_{j}\right)^{2}}\left[\left(1-W_{j}\right)\left\{v_{j}-\pi_{j}-o_{j}\right\}+\varepsilon_{j} \zeta_{j}\right],
\end{aligned}
$$




$$
\begin{aligned}
& \frac{\partial^{2} \operatorname{lnL}}{\partial \mathrm{c} \partial \lambda}=\frac{1}{\mathrm{c}^{3}} \sum_{\mathrm{j}=1}^{\mathrm{K}} \sum_{\mathrm{i}=1}^{\mathrm{r}_{\mathrm{j}}} \mathrm{s}_{\mathrm{j}}^{2 \mathrm{p}} \mathrm{B}_{\mathrm{ij}}-\sum_{\mathrm{j}=1}^{\mathrm{K}} \frac{\left(\mathrm{n}_{\mathrm{j}}-\mathrm{r}_{\mathrm{j}}\right)}{\left(1-\mathrm{W}_{\mathrm{j}}\right)^{2}}\left[\left(1-\mathrm{W}_{\mathrm{j}}\right)\left\{\vartheta_{j}-\varsigma_{j}-v_{j}\right\}+\varepsilon_{j} \Omega_{j}\right], \\
& \frac{\partial^{2} \ln L}{\partial p \partial \lambda}=-\frac{2}{c^{2}} \sum_{j=1}^{K} \sum_{i=1}^{r_{j}} s_{j}^{2 p} \ln s_{j} B_{i j}-\sum_{j=1}^{K} \frac{\left(n_{j}-r_{j}\right)}{\left(1-W_{j}\right)^{2}}\left\{\left(1-W_{j}\right)\left[\Theta_{j}+\Lambda_{j}+\frac{c}{\lambda} o_{j}\right]+\Omega_{j} \zeta_{j}\right\},
\end{aligned}
$$

where $\varphi^{\prime}$ is the derivative pdf of standard normal distribution,

$$
\begin{aligned}
& \eta_{j}=G_{j} \ln s_{j}^{2} \exp \left(G_{j}\right)\left[\Phi\left(H_{j}\right)\left\{1+G_{j}\right\}-2 c D_{j} \varphi\left(H_{j}\right)\right], \\
& \omega_{j}=c D_{j}\left\{\varphi^{\prime}\left(A_{j}\right)+\exp \left(G_{j}\right) \varphi^{\prime}\left(H_{j}\right)\right\}-\exp \left(G_{j}\right) \varphi\left(H_{j}\right)+\varphi\left(A_{j}\right), \\
& \zeta_{j}=c D_{j} \ln s_{j}\left(\varphi\left(A_{j}\right)-\exp \left(G_{j}\right) \varphi\left(H_{j}\right)\right)+G_{j} \ln s_{j} \exp \left(G_{j}\right) \Phi\left(H_{j}\right), \\
& \Psi_{j}=\left(1-W_{j}\right)\left\{-\frac{1}{c} \exp \left(G_{j}\right) \theta_{j}+D_{j} \gamma_{j}\right\}+\varepsilon_{j}^{2}, \\
& \theta_{j}=\left\{D_{j} \varphi\left(H_{j}\right)\left(2\left(G_{j}+1\right)\right)-\frac{1}{c} \Phi\left(H_{j}\right)\left(2+G_{j}\right)\right\}, \\
& \gamma_{j}=\left\{D_{j}\left(\varphi^{\prime}\left(A_{j}\right)+\exp \left(G_{j}\right) \varphi^{\prime}\left(H_{j}\right)\right)+\frac{2}{c} \varphi\left(A_{j}\right)\right\}, \\
& \varepsilon_{j}=\left\{D_{j}\left(\exp \left(G_{j}\right) \varphi\left(H_{j}\right)-\varphi\left(A_{j}\right)\right)-\frac{G_{j}}{c} \exp \left(G_{j}\right) \Phi\left(H_{j}\right)\right\}, \\
& \alpha_{j}=\left\{A_{j} \varphi^{\prime}\left(A_{j}\right)-\varphi\left(A_{j}\right)\right\} \\
& \sigma_{j}=\left\{\frac{1}{2 \lambda} \exp \left(G_{j}\right) H_{j} \varphi\left(H_{j}\right)\left(\frac{1}{\lambda}\left[\frac{1}{2}+G_{j}\right]+G_{j}\right)\right\}_{j}, \\
& \kappa_{j}=\left\{\frac{G_{j}^{2}}{\lambda} \Phi^{2}\left(H_{j}\right)-\frac{H_{j}^{2}}{4 \lambda} \varphi^{\prime}\left(H_{j}\right)\right\}, \\
& \Omega_{j}=\frac{1}{2 \lambda}\left(A_{j} \varphi\left(A_{j}\right)-H_{j} \exp \left(G_{j}\right) \varphi\left(H_{j}\right)\right)+\frac{G_{j}}{\lambda} \exp \left(G_{j}\right) \Phi\left(H_{j}\right), \\
& v_{j}=G_{j} D_{j} \ln s_{j} \exp \left(G_{j}\right) \varphi\left(H_{j}\right)\left(2+\frac{1}{G_{j}}-c D_{j} \frac{\varphi^{\prime}\left(H_{j}\right)}{G_{j} \varphi\left(H_{j}\right)}\right), \\
& \pi_{j}=D_{j} \ln s_{j}\left(\varphi\left(A_{j}\right)+c D_{j} \varphi^{\prime}\left(A_{j}\right)\right), \\
& \ln s_{j} \exp \left(G_{j}\right) \Phi\left(H_{j}\right)\left[1+G_{j}\right], \\
& \vartheta_{j}\left(H_{j}\right)\left(\frac{1}{H_{j}}\left(1+\frac{1}{2 G_{j}}\right)+\frac{\varphi^{\prime}\left(H_{j}\right)}{2 G_{j} \varphi\left(H_{j}\right)}-\frac{1}{2 c D_{j}}\right),
\end{aligned}
$$




$$
\begin{aligned}
& \varsigma_{j}=\frac{2}{c \lambda} G_{j} \exp \left(G_{j}\right) \Phi\left(H_{j}\right), \\
& v_{j}=\frac{D_{j}}{2 \lambda}\left(\varphi\left(A_{j}\right)+A_{j} \varphi^{\prime}\left(A_{j}\right)\right), \\
& \Theta_{j}=\frac{1}{2 \lambda} c D_{j} \ln s_{j}\left(\varphi\left(A_{j}\right)+A_{j} \varphi^{\prime}\left(A_{j}\right)\right), \\
& \text { and } \Lambda_{j}=\frac{1}{2 \lambda} c D_{j} \ln s_{j} G_{j} \exp \left(G_{j}\right) \varphi\left(H_{j}\right)\left(\frac{1}{G_{j}}\left\{1+\frac{H_{j} \varphi^{\prime}\left(H_{j}\right)}{\varphi\left(H_{j}\right)}\right\}-\frac{H_{j}}{c D_{j}}-2\right) .
\end{aligned}
$$

Therefore, the maximum likelihood estimators of $\mathrm{C}, \mathrm{P}$ and $\lambda$, have an asymptotic variance-covariance matrix obtained by inverting Fisher information matrix defined in equation (3.6). The observed Fisher information matrix enables us to construct $\mathrm{CI}$ for the parameters based on the limiting normal distribution through simulation.

\subsection{Prediction of the Scale Parameter and the Reliability Function}

To predict the value of the scale parameter $\mu_{u}$ under the usual stress $V_{u}$,

the invariance property of ML estimator is used as follows

$\hat{\mu}_{u}=\hat{C} S_{u}^{-\hat{p}}$,

where

$$
S_{u}=\frac{V_{u}}{V^{*}},
$$

The MLE of the reliability function at the lifetime $t_{0}$ under usual stress $V_{u}$, is given by

$$
\hat{R}_{u}\left(t_{0}\right)=1-\left[\Phi\left[\left(\frac{\hat{\lambda}}{t_{0}}\right)^{\frac{1}{2}}\left(\frac{t_{0}}{\hat{\mu}_{u}}-1\right)\right]+\exp \left(\frac{2 \hat{\lambda}}{\hat{\mu}_{u}}\right) \Phi\left[-\left(\frac{\hat{\lambda}}{t_{0}}\right)^{\frac{1}{2}}\left(\frac{t_{0}}{\hat{\mu}_{u}}+1\right)\right]\right] .
$$

\section{Simulation Studies}

This Section presents the numerical values of the Maximum Likelihood Estimates (MLE`s) of the unknown parameters C, P and $\lambda$, their Estimated Mean Squared Errors (EMSE`s), Relative Absolute Biases (RAB`s), Lower 
Bound (LB`s), Upper Bound (UB`s) and CI, lengths, the estimated of scale parameter $\mu$ and the reliability function $t_{0}$ under normal use conditions $V_{u}$ and its EMSE`s.

The numerical solution is performed according to the following steps

- For given values of $C, \mathrm{P}, \lambda$ and stress level $V_{j}, j=1,2,3$, the estimated values of $\mu_{j}, j=1,2,3$ are calculated according to (2.5).

- Generate a random sample of size $\mathrm{n}$ from the 2-parameter IG distribution and obtain the observations for given values of $n_{j}$ and $r_{j}, j=1,2, \ldots, K$, and different values of $c_{0}, p_{0}, \mu_{0}$ and $\lambda_{0}$.

- Based on the values of $n_{j}, r_{j}, t_{i j}, V_{j}, i=1,2, \ldots, r_{j}, j=1,2, \ldots, K$ and $V_{u}$, the MLE`s, and their EMSE`s, RAB`s, LB`s, and UB`s, in additional to $\hat{\mu}_{u}$ and $\hat{R}_{u}\left(t_{0}\right)$, are obtained.

- The steps are repeated more than 500 times until getting the MLE`s as shown in Table 1.

The numerical results which are placed in Tables 1to 4 are based on $n_{1}=20, n_{2}=20, n_{3}=20, r_{1}=7, r_{2}=5, r_{3}=4, V_{1}=1, V_{2}=1.5$ and $V_{3}=2$.

For different values of $\lambda_{0}, C_{0}$, and $P_{0}$, Table 1 , summarizes the results of solving the ML equations of $C, P, \lambda$, and of computing $\mu_{1}, \mu_{2}$, and $\mu_{3}$, with their RAB`s and EMSE`s. Generally it is evident that the EMSE's of the scale parameter $\mu_{j}, j=1,2,3$ tend to increases as the stress value $V_{j}, j=1,2,3$ increases and the EMSE's of $P$ is the smallest one and converges to zero. While, in the Table 2, the asymptotic variance-covariance matrix for different values of $\lambda_{0}, C_{0}$, and $P_{0}$ is computed. It is evident that the variance of $P$ is the smallest one and converges to zero. Also, it is seen from Table 2, that the covariance between $\lambda$ and $P$ is the smallest one. In Table 3 the confidence limits for different values of $\lambda_{0}, C_{0}$, and $P_{0}$ are computed. It is evident that the interval length of $P$ is the smallest one. Also, it is seen from Table 3, that the interval lengths of the scale parameter $\mu_{\mathrm{j}}, \mathrm{j}=1,2,3$ tend to decreases as the stress value $V_{j}, j=1,2,3$ decreases. The scale parameter $\mu_{u}$ under the usual condition stress $V_{j}$, is predicted for different values 
of $\lambda_{0}, C_{0}$, and $P_{0}$ using equation (3.13). The reliability function also predicted for different values mission time, using equation (3.14). Table 4 presents the predicted values of the scale parameter and the reliability function. In general, it is seen that the reliability decreases when the mission time $t_{0}$ increases. While, in the Table 4, the results EMSE's of the reliability are better when $P_{0}=.1$. 
Table 1: The MLE`s, RAB`s, and EMSE`s

\begin{tabular}{|c|c|c|c|c|c|c|}
\hline $\mathrm{C}_{0}$ & $\mathrm{P}_{0}$ & $\lambda_{0}$ & Parameter & MLE'S & RAB`s & EMSE'S \\
\hline \multirow[t]{6}{*}{1.5} & .2 & .17 & C & 1.126 & 0.06 & 0.013 \\
\hline & & & $\mathrm{P}$ & 0.2 & $1 \mathrm{E}-3$ & $2.0 \mathrm{E}-5$ \\
\hline & & & $\lambda$ & 0.099 & 0.418 & $5.4 \mathrm{E}-3$ \\
\hline & & & $\mu_{1}$ & 1.328 & 0.06 & 0.011 \\
\hline & & & $\mu_{2}$ & 1.44 & 0.06 & 0.013 \\
\hline & & & $\mu_{3}$ & 1.525 & 0.06 & 0.015 \\
\hline \multirow[t]{6}{*}{1.7} & 0.6 & & $\mathrm{C}$ & 1.608 & 0.054 & $9.2 \mathrm{E}-3$ \\
\hline & & & $\mathrm{P}$ & 0.6 & $1.3 \mathrm{E}-4$ & $1.9 \mathrm{E}-4$ \\
\hline & & & $\lambda$ & 0.099 & 0.416 & $5.4 \mathrm{E}-3$ \\
\hline & & & $\mu_{1}$ & 1.343 & 0.054 & $6.4 \mathrm{E}-3$ \\
\hline & & & $\mu_{2}$ & 1.713 & 0.054 & 0.011 \\
\hline & & & $\mu_{3}$ & 2.035 & 0.054 & 0.015 \\
\hline \multirow[t]{6}{*}{3} & 0.5 & & $\mathrm{C}$ & 2.901 & 0.033 & 0.02 \\
\hline & & & $\mathrm{P}$ & 0.5 & $6.1 \mathrm{E}-4$ & $1.2 \mathrm{E}-4$ \\
\hline & & & $\lambda$ & 0.098 & 0.425 & $5.5 \mathrm{E}-3$ \\
\hline & & & $\mu_{1}$ & 2.497 & 0.033 & 0.015 \\
\hline & & & $\mu_{2}$ & 3.058 & 0.033 & 0.023 \\
\hline & & & $\mu_{3}$ & 3.531 & 0.033 & 0.031 \\
\hline \multirow[t]{6}{*}{1.5} & .1 & .13 & $\mathrm{C}$ & 1.426 & 0.049 & $7.0 \mathrm{E}-3$ \\
\hline & & & $\mathrm{P}$ & 0.099 & $5 \mathrm{E}-3$ & $3.5 \mathrm{E}-5$ \\
\hline & & & $\lambda$ & 0.075 & 0.423 & $3.2 \mathrm{E}-3$ \\
\hline & & & $\mu_{1}$ & 1.384 & 0.049 & $6.5 \mathrm{E}-3$ \\
\hline & & & $\mu_{2}$ & 1.441 & 0.049 & 7.2E-3 \\
\hline & & & $\mu_{3}$ & 1.483 & 0.049 & $7.7 \mathrm{E}-3$ \\
\hline \multirow[t]{6}{*}{1.7} & & .14 & $\mathrm{C}$ & 1.62 & 0.04 & $6.4 \mathrm{E}-3$ \\
\hline & & & $\mathrm{P}$ & 0.1 & $3.1 \mathrm{E}-3$ & $5.1 \mathrm{E}-5$ \\
\hline & & & $\lambda$ & 0.08 & 0.42 & $3.7 \mathrm{E}-3$ \\
\hline & & & $\mu_{1}$ & 1.57 & 0.04 & $6.1 \mathrm{E}-3$ \\
\hline & & & $\mu_{2}$ & 1.64 & 0.04 & $6.5 \mathrm{E}-3$ \\
\hline & & & $\mu_{3}$ & 1.68 & 0.04 & $6.9 \mathrm{E}-3$ \\
\hline \multirow[t]{6}{*}{1.6} & & .15 & $\mathrm{C}$ & 1.51 & 0.05 & $7.2 \mathrm{E}-3$ \\
\hline & & & $\mathrm{P}$ & 0.1 & 4.7E-5 & 7.3E-11 \\
\hline & & & $\lambda$ & 0.08 & 0.42 & $4.2 \mathrm{E}-3$ \\
\hline & & & $\mu_{1}$ & 1.47 & 0.05 & $6.8 \mathrm{E}-3$ \\
\hline & & & $\mu_{2}$ & 1.53 & 0.05 & 7.3E-3 \\
\hline & & & $\mu_{3}$ & 1.57 & 0.05 & $7.8 \mathrm{E}-3$ \\
\hline
\end{tabular}


Table 1: The MLE`s, RAB`s, and EMSE`s (Cont.)

\begin{tabular}{|c|c|c|c|c|c|c|}
\hline $\mathrm{C}_{0}$ & $\mathrm{P}_{0}$ & $\lambda_{0}$ & Parameter & MLE'S & RAB's & EMSE`S \\
\hline \multirow[t]{18}{*}{1.2} & .7 & .1 & $\mathrm{C}$ & 1.18 & 0.06 & 0.4 \\
\hline & & & $\mathrm{P}$ & 0.7 & 3..9E-4 & $1.2 \mathrm{E}-5$ \\
\hline & & & $\lambda$ & 0.07 & 0.41 & $3.1 \mathrm{E}-3$ \\
\hline & & & $\mu_{1}$ & 0.95 & 0.01 & 0.03 \\
\hline & & & $\mu_{2}$ & 1.27 & 0.01 & 0.05 \\
\hline & & & $\mu_{3}$ & 1.55 & 0.01 & 0.07 \\
\hline & .7 & .14 & $\mathrm{C}$ & 1.23 & 0.03 & 0.08 \\
\hline & & & $\mathrm{P}$ & 0.7 & $3.8 \mathrm{E}-4$ & $1.5 \mathrm{E}-5$ \\
\hline & & & $\lambda$ & 0.08 & 0.415 & $3.6 \mathrm{E}-3$ \\
\hline & & & $\mu_{1}$ & 1.003 & 0.03 & 0.05 \\
\hline & & & $\mu_{2}$ & 1.33 & 0.03 & 0.09 \\
\hline & & & $\mu_{3}$ & 1.62 & 0.03 & 0.13 \\
\hline & 19 & .15 & $\mathrm{C}$ & 1.27 & 0.05 & 0.09 \\
\hline & & & $\mathrm{P}$ & 0.19 & $1.1 \mathrm{E}-3$ & $1.8 \mathrm{E}-5$ \\
\hline & & & $\lambda$ & 0.08 & 0.41 & $4.2 \mathrm{E}-3$ \\
\hline & & & $\mu_{1}$ & 1.2 & 0.05 & 0.08 \\
\hline & & & $\mu_{2}$ & 1.29 & 0.05 & 0.10 \\
\hline & & & $\mu_{3}$ & 1.36 & 0.05 & 0.11 \\
\hline
\end{tabular}


Table 2: The Confidence Intervals

\begin{tabular}{|c|c|c|c|c|c|c|}
\hline $\mathrm{C}_{0}$ & $\overline{P_{0}}$ & $\lambda_{0}$ & Parameter & L.B & U.B & Length \\
\hline \multirow{6}{*}{1.5} & .2 & .17 & $\mathrm{C}$ & 1.285 & 1.535 & 0.25 \\
\hline & & & $\mathrm{P}$ & 0.192 & 0.208 & 0.016 \\
\hline & & & $\lambda$ & 0.063 & 0.135 & 0.072 \\
\hline & & & $\mu_{1}$ & 1.211 & 1.445 & 0.234 \\
\hline & & & $\mu_{2}$ & 1.312 & 1.568 & 0.256 \\
\hline & & & $\mu_{3}$ & 1.389 & 1.662 & 0.273 \\
\hline \multirow{6}{*}{1.7} & .6 & & $\mathrm{C}$ & 1.558 & 1.657 & 0.099 \\
\hline & & & $\mathrm{P}$ & 0.575 & 0.625 & 0.051 \\
\hline & & & $\lambda$ & 0.062 & 0.137 & 0.075 \\
\hline & & & $\mu_{1}$ & 1.303 & 1.382 & 0.079 \\
\hline & & & $\mu_{2}$ & 1.658 & 1.767 & 0.108 \\
\hline & & & $\mu_{3}$ & 1.966 & 2.105 & 0.139 \\
\hline \multirow[t]{6}{*}{3} & .5 & & $\mathrm{C}$ & 2.714 & 3.087 & 0.372 \\
\hline & & & $\mathrm{P}$ & 0.479 & 0.52 & 0.04 \\
\hline & & & $\lambda$ & 0.062 & 0.133 & 0.071 \\
\hline & & & $\mu_{1}$ & 2.34 & 2.653 & 0.313 \\
\hline & & & $\mu_{2}$ & 2.86 & 3.256 & 0.396 \\
\hline & & & $\mu_{3}$ & 3.298 & 3.764 & 0.466 \\
\hline \multirow[t]{6}{*}{1.5} & .1 & .13 & $\mathrm{C}$ & 1.353 & 1.499 & 0.146 \\
\hline & & & $\mathrm{P}$ & 0.089 & 0.11 & 0.021 \\
\hline & & & $\lambda$ & 0.048 & 0.102 & 0.055 \\
\hline & & & $\mu_{1}$ & 1.314 & 1.454 & 0.14 \\
\hline & & & $\mu_{2}$ & 1.367 & 1.515 & 0.148 \\
\hline & & & $\mu_{3}$ & 1.406 & 1.561 & 0.155 \\
\hline \multirow[t]{6}{*}{1.7} & & .14 & $\mathrm{C}$ & 1.586 & 1.659 & 0.073 \\
\hline & & & $\mathrm{P}$ & 0.087 & 0.113 & 0.026 \\
\hline & & & $\lambda$ & 0.051 & 0.11 & 0.059 \\
\hline & & & $\mu_{1}$ & 1.538 & 1.611 & 0.073 \\
\hline & & & $\mu_{2}$ & 1.603 & 1.677 & 0.074 \\
\hline & & & $\mu_{3}$ & 1.649 & 1.726 & 0.077 \\
\hline \multirow[t]{6}{*}{1.6} & & .15 & $\mathrm{C}$ & 1.479 & 1.557 & 0.079 \\
\hline & & & $\mathrm{P}$ & 0.1 & 0.1 & $2.5 \mathrm{E}-5$ \\
\hline & & & $\lambda$ & 0.055 & 0.118 & 0.063 \\
\hline & & & $\mu_{1}$ & 1.435 & 1.511 & 0.076 \\
\hline & & & $\mu_{2}$ & 1.494 & 1.574 & 0.079 \\
\hline & & & $\mu_{3}$ & 1.538 & 1.62 & 0.082 \\
\hline
\end{tabular}


Table 2: The Confidence Intervals (Cont.)

\begin{tabular}{|c|c|c|c|c|c|c|}
\hline $\mathrm{C}_{0}$ & $\mathrm{P}_{0}$ & $\lambda_{0}$ & Parameter & L.B & U.B & Length \\
\hline \multirow{18}{*}{1.2} & \multirow[t]{6}{*}{.7} & \multirow{6}{*}{.13} & C & 0.792 & 1.57 & 0.778 \\
\hline & & & $\mathrm{P}$ & 0.694 & 0.707 & 0.012 \\
\hline & & & $\lambda$ & 0.047 & 0.106 & 0.059 \\
\hline & & & $\mu_{1}$ & 0.639 & 1.276 & 0.636 \\
\hline & & & $\mu_{2}$ & 0.854 & 1.689 & 0.835 \\
\hline & & & $\mu_{3}$ & 1.049 & 2.062 & 1.013 \\
\hline & \multirow[t]{6}{*}{.7} & \multirow[t]{6}{*}{.14} & $\mathrm{C}$ & 0.728 & 1.747 & 1.019 \\
\hline & & & $\mathrm{P}$ & 0.693 & 0.707 & 0.014 \\
\hline & & & $\lambda$ & 0.05 & 0.113 & 0.063 \\
\hline & & & $\mu_{1}$ & 0.587 & 1.419 & 0.831 \\
\hline & & & $\mu_{2}$ & 0.784 & 1.879 & 1.095 \\
\hline & & & $\mu_{3}$ & 0.963 & 2.294 & 1.331 \\
\hline & \multirow[t]{6}{*}{.19} & \multirow[t]{6}{*}{.15} & $\mathrm{C}$ & 0.715 & 1.826 & 1.111 \\
\hline & & & $\mathrm{P}$ & 0.182 & 0.197 & 0.015 \\
\hline & & & $\lambda$ & 0.054 & 0.122 & 0.068 \\
\hline & & & $\mu_{1}$ & 0.675 & 1.725 & 1.049 \\
\hline & & & $\mu_{2}$ & 0.729 & 1.863 & 1.134 \\
\hline & & & $\mu_{3}$ & 0.77 & 1.963 & 1.197 \\
\hline
\end{tabular}


Table 3: The Asymptotic Variance-Covariance Matrix

\begin{tabular}{|c|c|c|c|c|c|c|}
\hline $\mathrm{C}_{0}$ & $\mathrm{P}_{0}$ & $\lambda_{0}$ & $\begin{array}{c}\text { Paramet } \\
\text { er }\end{array}$ & C & $\mathbf{P}$ & $\lambda$ \\
\hline 1.5 & .2 & .17 & $\begin{array}{l}\mathrm{C} \\
\mathrm{P} \\
\lambda\end{array}$ & $4.7 \mathrm{E}-3$ & $\begin{array}{l}1.2 \mathrm{E}-4 \\
2 \mathrm{E}-5\end{array}$ & $\begin{array}{c}4.4 \mathrm{E}-4 \\
5.5 \mathrm{E}-6 \\
4 \mathrm{E}-4\end{array}$ \\
\hline 1.7 & .6 & & $\begin{array}{l}\mathrm{C} \\
\mathrm{P} \\
\lambda\end{array}$ & 7.5E-4 & $\begin{array}{l}1.1 \mathrm{E}-4 \\
1.9 \mathrm{E}-4\end{array}$ & $\begin{array}{c}5.3 \mathrm{E}-4 \\
-1.9 \mathrm{E}-6 \\
4.2 \mathrm{E}-4\end{array}$ \\
\hline 3 & .5 & & $\begin{array}{l}\mathrm{C} \\
\mathrm{P} \\
\lambda\end{array}$ & 0.01 & $\begin{array}{l}1.0 \mathrm{E}-3 \\
1.2 \mathrm{E}-4\end{array}$ & $\begin{array}{l}.8 \mathrm{E}-4 \\
1.3 \mathrm{E}-3 \\
3.8 \mathrm{E}-4 \\
\end{array}$ \\
\hline 1.5 & .1 & .13 & $\begin{array}{l}\mathrm{C} \\
\mathrm{P} \\
\lambda\end{array}$ & $1.6 \mathrm{E}-3$ & $\begin{array}{l}9.9 \mathrm{E}-5 \\
3.4 \mathrm{E}-5\end{array}$ & $\begin{array}{l}3.1 \mathrm{E}-4 \\
8.8 \mathrm{E}-7 \\
2.2 \mathrm{E}-4\end{array}$ \\
\hline 1.7 & & .14 & $\begin{array}{l}\mathrm{C} \\
\mathrm{P} \\
\lambda\end{array}$ & $4.0 \mathrm{E}-4$ & $\begin{array}{l}-8.1 \mathrm{E}-6 \\
5.1 \mathrm{E}-5\end{array}$ & $\begin{array}{c}3.2 \mathrm{E}-4 \\
-7.7 \mathrm{E}-6 \\
2.6 \mathrm{E}-4 \\
\end{array}$ \\
\hline 1.6 & & .15 & $\begin{array}{l}\mathrm{C} \\
\mathrm{P} \\
\lambda\end{array}$ & $4.7 \mathrm{E}-4$ & $\begin{array}{c}6.8 \mathrm{E}-9 \\
5.0 \mathrm{E}-11\end{array}$ & $\begin{array}{c}3.7 \mathrm{E}-4 \\
1.4 \mathrm{E}-8 \\
3 \mathrm{E}-4 \\
\end{array}$ \\
\hline 1.2 & .7 & .13 & $\begin{array}{l}\mathrm{C} \\
\mathrm{P} \\
\lambda\end{array}$ & 0.04 & $\begin{array}{l}-6.6 \mathrm{E}-4 \\
1.1 \mathrm{E}-5\end{array}$ & $\begin{array}{r}-6.8 \mathrm{E}-4 \\
9.7 \mathrm{E}-6 \\
2.6 \mathrm{E}-4 \\
\end{array}$ \\
\hline & .7 & .14 & $\begin{array}{l}\mathrm{C} \\
\mathrm{P} \\
\lambda\end{array}$ & 0.08 & $\begin{array}{l}-8.7 \mathrm{E}-4 \\
1.5 \mathrm{E}-5\end{array}$ & $\begin{array}{c}-1.8 \mathrm{E}-3 \\
1.8 \mathrm{E}-5 \\
3 \mathrm{E}-4\end{array}$ \\
\hline & .19 & .15 & $\begin{array}{l}\mathrm{C} \\
\mathrm{P} \\
\lambda\end{array}$ & 0.09 & $\begin{array}{l}8.1 \mathrm{E}-3 \\
1.8 \mathrm{E}-5\end{array}$ & $\begin{array}{c}-2.7 \mathrm{E}-3 \\
2.5 \mathrm{E}-6 \\
3.5 \mathrm{E}-4\end{array}$ \\
\hline
\end{tabular}


Table 4: Estimates of $\mu$ and $R\left(t_{0}\right)$ under normal conditions

\begin{tabular}{|c|c|c|c|c|c|c|}
\hline $\mathrm{C}_{0}$ & $\mathrm{P}_{0}$ & $\lambda_{0}$ & $\hat{\mu}_{\mathrm{u}}$ & $\mathrm{t}_{0}$ & $\hat{\mathrm{R}}_{\mathrm{u}}\left(\mathrm{t}_{0}\right)$ & EMSE`s \\
\hline \multirow[t]{4}{*}{1.5} & .2 & .17 & 1.049 & .30 & 0.189 & 0.083 \\
\hline & & & & .35 & 0.148 & \\
\hline & & & & .40 & 0.114 & \\
\hline & & & & .45 & 0.085 & \\
\hline \multirow[t]{4}{*}{1.7} & .6 & & 1.248 & .49 & 0.079 & 0.086 \\
\hline & & & & .54 & 0.058 & \\
\hline & & & & .59 & 0.039 & \\
\hline & & & & .64 & 0.022 & \\
\hline \multirow[t]{4}{*}{3} & .5 & & 1.615 & .49 & 0.085 & 0.092 \\
\hline & & & & .54 & 0.064 & \\
\hline & & & & .59 & 0.045 & \\
\hline & & & & .64 & 0.028 & \\
\hline \multirow[t]{4}{*}{1.5} & .1 & .13 & 1.025 & .13 & 0.368 & 0.079 \\
\hline & & & & .15 & 0.323 & \\
\hline & & & & .17 & 0.285 & \\
\hline & & & & .19 & 0.252 & \\
\hline \multirow[t]{4}{*}{1.7} & & .14 & 1.039 & .13 & 0.388 & 0.078 \\
\hline & & & & .15 & 0.342 & \\
\hline & & & & .17 & 0.303 & \\
\hline & & & & .19 & 0.27 & \\
\hline \multirow[t]{4}{*}{1.6} & & .15 & 1.032 & .03 & 0.873 & 0.035 \\
\hline & & & & .05 & 0.732 & \\
\hline & & & & .07 & 0.621 & \\
\hline & & & & .09 & 0.535 & \\
\hline \multirow[t]{12}{*}{1.2} & .7 & .13 & 1.044 & .03 & 0.844 & 0.039 \\
\hline & & & & .05 & 0.695 & \\
\hline & & & & .07 & 0.583 & \\
\hline & & & & .09 & 0.498 & \\
\hline & .7 & .14 & 1.078 & .03 & 0.861 & 0.036 \\
\hline & & & & .05 & 0.717 & \\
\hline & & & & .07 & 0.606 & \\
\hline & & & & .09 & 0.521 & \\
\hline & .19 & .15 & 1.026 & .01 & 0.996 & 0.042 \\
\hline & & & & .06 & 0.678 & \\
\hline & & & & .11 & 0.472 & \\
\hline & & & & .16 & 0.349 & \\
\hline
\end{tabular}

\section{Conclusion}

In this paper, we have discussed the maximum likelihood estimators of the parameters based on Type-II censoring. The data failure times at each 
stress level are assumed to follow the 2-parameter IG distribution with scale parameter that is an inverse power law function. The IG distribution has been extensively used in many different areas and it was very useful in a wide variety of applications, especially in the analysis of marketing research also used in the area of natural and social sciences. This distribution serves as a good model for accelerated life tests. The ML estimators, Fisher in formation matrix, the asymptomatic variancecovariance matrix and the confidence intervals are founded. The prediction of the value of the scale parameter and the reliability function under the usual conditions stress are obtained for various combinations of the model parameters. Finally, Monte Carlo simulation studies were presented for illustrating the theoretic cal results. For different values of the parameters, it is seen that the EMSE's of the scale parameter tend to decreases as the stress value decreases. Also, it is evident that the variance, EMSE's and the interval length of $P$ are the smallest ones. Moreover, it is seen that the reliability decreases when the mission time increases.

\section{References}

1 Abdel-Ghaly, A. A., Attia, A. F., and Aly, H. M. (1998). Estimation of the Parameters of Pareto Distribution and the Reliability Function Using Accelerated Life Testing with Censoring. Communications in Statistics, Simulation and Computation, 27, 469-484.

2 AL-Hussaini, E. K., and Abdel-Hamid, A. H. (2004). Bayesian Estimation of the Parameters, Reliability and Hazard Rate Functions of Mixtures under Accelerated Life Tests. Communications in Statistics, Simulation and Computation, 33(4), 963-982.

3 AL-Hussaini, E. K., and Abdel-Hamid, A. H. (2006). Accelerated Life Tests under Finite Mixture Models. Communications in Statistics, Simulation and Computation, 76, 8, 673-690. 
4 Bai, D. S., and Chung, S. W. (1989). Accelerated Life Test Model with the Inverse Power Law Model. Reliability Engineering and System Safety, 24, 223-230.

5 Bannarjee, A. K., and Bhattacharyya, G. K. (1976). A Purchase Incidence Model with Inverse Gaussian Inter Purchase Times. Journal of American Statistics Association, 71, 823-829.

6 Bhattacharyya, G.K., and Fries, A. (1982). Fatigue Failure Models Bimbaum Saunders VS. Inverse Gaussian. IEEE Transactions on reliability, R-31, 5, 439-441.

7 Bugaighis, M. M. (1990). Properties of the MLE for Parameters of a Weibull Regression Model under Type-I Censoring. IEEE Transactions on Reliability, 39, 102-105.

8 Chhikara, R. S., and Folks, J. L. (1976). Optimum Test Procedures for the Mean of First Passage Time Distribution in Brownian Motion with Positive Drift. Technometrics, 18,189-193.

9 Chhikara, R. S., and Folks, J. L. (1989). The Inverse Gaussian Distribution. Marcel Dekker, New York.

10 Eaton, W.W., and Whitmore, G. A. (1977). Length of Stay as A Stochastic Process: A General Approach and Application to Hospitalization for Schizophrema. Journal of Mathematical Social, 5, 273-292.

11 El-Dessouky, E. A. (2001). On the Use of Bayesian Approach in Accelerated Life Testing. M.Sc. Thesis, Institute of Statistical Studies and Research, Cairo University, Egypt.

12 Johnson, N., Kotz, S., and Balakrishnan, N. (1995). Continuous Univariate Distributions. Wiley: New York, U.S.A. 
13 Kim, C. M., and Bai, D. S. (2002). Analysis of Accelerated Life Test Data under Two Failure Modes. International Journal of Reliability, Quality and Safety Engineering, 9, 111-125.

14 Lancaster, A. (1972). Stochastic Model for the Duration of a Strike. Royal Statistical Society, A, 135, 257-271.

15 Lawless, J. F. (1976). Confidence Interval Estimation in the Inverse Power Law Model. Royal Statistical Society, 25, 128-138.

16 Marcus, A. H. (1975). Some Exact Distributions in Traffic Noise Theory Advance. In applied Probability, 7, 593-606.

17 McCool, J. I. (1980). Confidence Limits for Weibull Regression with Censored Data. IEEE Transactions on Reliability, 29, 145-150.

18 Meeker, W. Q., and Escobar, L. A. (1998). Statistical Methods for Reliability Data. New York: John Wiley \& Sons.

19 Mudholkar, G., and Natarajan, R. (2002). The Inverse Gaussian Models: Analogues of Symmetry, Skewness and Kurtosis. Annals of the Institute of Statistical Mathematics, 54, 138-154.

20 Nelson, W. (1982). Applied life data analysis. Wiley: New York, U.S.A.

21 Nelson, W. (1990). Accelerated Life Testing: Statistical Models, Test Plan and Data Analysis. Wiley: New York, U.S.A.

22 Seshadri, V. (1993). The Inverse Gaussian Distribution: A Case Study in Exponential Families. Claredon, New York, U.S.A.

23 Tweedie, M.C.K. (1957). Statistical properties of Inverse Gaussian Distribution. Annals of Mathematical Statistics, 28, 362-377. 
24 Vander Wiel, S.A., and Meeker, W.Q. (1990). Accuracy of Approximate Confidence Bounds Using Censored Weibull Regression Data from Accelerated Life Tests. IEEE Tran. on Reliability, 39, 346351.

25 Watkins, A. J. (1991). On the Analysis of Accelerated Life Testing Experiments. IEEE Transactions on Reliability, 40, 98-101.

26 Watkins, A. J., and John, A. M. (2008). On Constant Stress Accelerated Life Tests Terminated by Type-II Censoring at One of the Stress Levels. Journal of Statistical Planning and Inference, 138, 768786.

27 Wise, M.E. (1966). Tracer Dilution Curves in Cardiology and Random Walk and Log-Normal Distribution. Act Physiological Pharmacological Neerlandica, 14, 175-204. 